Article

\title{
Linking HRM Practices and Institutional Setting to Collective Turnover: An Empirical Exploration
}

\author{
Dirk Van Dierendonck ${ }^{1, *}$, Arthur Lankester ${ }^{2}$, Maria Zmyslona ${ }^{1}$ and Hans Rothweiler ${ }^{3}$ \\ 1 Department of Organisation and Personnel Management, RSM Erasmus University, Burg Oudlaan 50, \\ Rotterdam 3062 PA, The Netherlands; Zmyslona.maria@gmail.com \\ 2 Inovus Institute, Amsterdam 1012 WX, The Netherlands; arthur.lankester@i-novus.org \\ 3 Top Employers Institute, Herengracht 208-216, Amsterdam 1016 BS, The Netherlands; \\ hans.rothweiler@top-employers.com \\ * Correspondence: DvDierendonck@rsm.nl; Tel.: +31-20-408-9569
}

Academic Editor: Isabella Proeller

Received: 16 June 2016; Accepted: 10 November 2016; Published: 6 December 2016

\begin{abstract}
The present study addresses the relationship between human resources management (HRM) practices and employee turnover by taking into account the influence of socioeconomic environment. Data was collected at company level with an international sample of 830 companies from 12 countries (Netherlands, Belgium, United Kingdom, Brazil, Switzerland, China, France, Italy, Poland, Germany, South Africa, and Spain). A division into four bundles of human resources (HR) practices is introduced: remunerative, communication, developmental, and well-being practices. The influence of the socioeconomic environment was factored in by including the institutional setting in terms of the level of coordination as a country-level variable. The results showed that collective turnover is related to both a country's institutional determinants and to company HR practices. Remunerative HR practices may have a negative influence in terms of enhancing turnover, particularly within countries high in coordination. HR well-being practices are the most beneficial practices in terms of reducing employee turnover. Our study adds to our knowledge on the relation between HR practices and turnover from an international perspective. It complements the empirical knowledge on the effectiveness of HRM practices in a cross-national setting and supports the notion that the institutional context should be given more attention when studying HR effectiveness.
\end{abstract}

Keywords: HRM practices; collective turnover; institutional context

\section{Introduction}

Turnover has been a focus of interest for human resources (HR) professionals for a long time, and retention of especially their top talent has been and is likely to remain their priority. In the current-day economy, it is the talents, capabilities and ideas of knowledge workers that are a company's main asset, rather than an organization's physical or financial assets [1]. In this paper, we focus on collective turnover, i.e., the cumulative level of employees leaving at the organizational level. It has been argued that human resources are most valuable and inimitable when people remain within an organization and develop themselves into the experienced professionals they are now, especially when their skills and knowledge are specific to the firm [2,3]. Collective turnover of employees can therefore seriously undermine the competiveness of an organization and lead to underperforming in comparison to main competitors [3], diminishing customer service and lowering quality and safety [4]. Low collective turnover rate on the other hand may protect such firm-specific human capital from imitation by competitors. In other words, turnover can be a major threat to a firm's competitive advantage especially for those companies where human capital drives success. Acknowledging that the impact of HR practices on employee attitudes and behaviors in general is well established, as is the link 
between consistent HR management best practices and organizational performance [5,6], we would still like to argue that the full story on key determinants of collective turnover is not told because most studies ignore the institutional context. Extending recent theorizing by Nyberg and Ployhart [7], our basic premise is that HR professionals can only be held partly responsible for the turnover of their employees, given that collective turnover is also influenced by the socioeconomic environment in which a company operates.

Companies are based within countries that have their own rules and customs. As such, the human resources management (HRM) practices within those companies do not function in a vacuum, given that the institutional setting of a country is likely to influence their effectiveness. As was noted by Nyberg and Ployhart [7], most research on collective turnover has focused on individual determinants and neglected the institutional context. The few studies that have specifically examined the joint influence of HRM practices and institutional setting reported mixed results [8]. This institutional context differs between countries as it is grounded in different legal histories. As a case in point, Rizov and Croucher's [9] examination of the impact of HRM practices on turnover across Europe showed contrary findings to those of Gooderham et al. [10] on profitability. In addition, none of these studies included emerging economies such as Brazil or China in their setup. However, due to institutional differences between European and emerging economies, it becomes likely that the impact of HR practices may be different [11]. Our sample includes not only nine European countries but also three emerging economies: Brazil, China and South Africa. The main research question of this article is to clarify the relationship between HRM practices and collective turnover at company level, taking into account a country-level institutional justification to provide a deeper understanding of the process differences between different countries, thereby addressing an existing gap in research and theory in this field.

Our study contributes to the international HR field in three important ways. First, previous studies combine practices mostly with a one- or two-dimensional approach, such as Boselie, et al.'s [12] approach to high performance practices and the seminal work of Gooderham et al. [13]. Building on their work, we introduce four bundles of HR practices: remunerative practices, communication practices, developmental practices and well-being practices. Especially HR well-being practices are seldom explicitly defined as a separate division of HR practices. We will argue and show that this is a serious omission when it comes to understanding collective turnover. Second, we provide a way to measure institutional distance in terms of a coordination index that uses relative recent data and incorporates more countries, including most notably the so-called BRIC countries (Brazil, Russia, India and China). This may stimulate more much-needed research in this area. Third, we provide additional empirical insight into how the institutional context of a country may influence the effectiveness of HR practices. The overall conceptual model guiding our research is depicted in Figure 1.

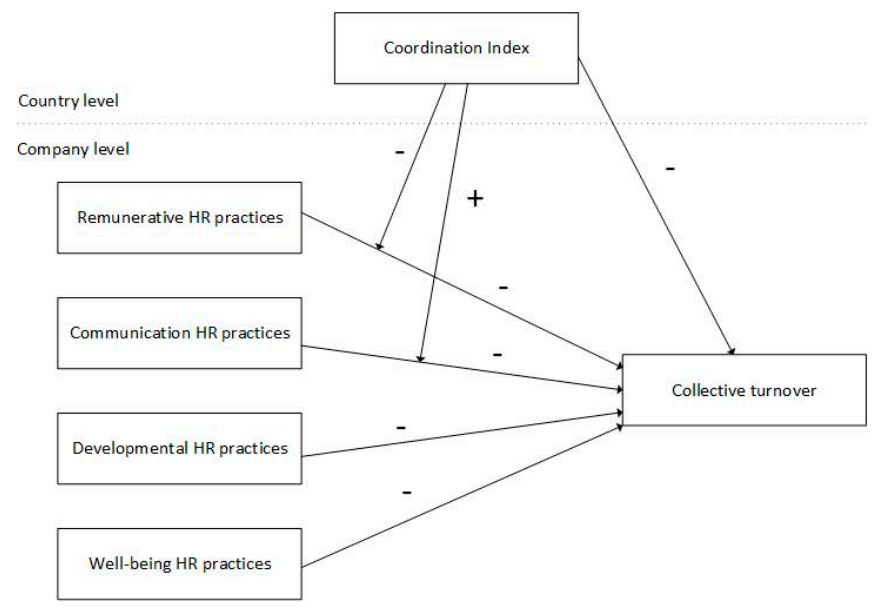

Figure 1. Conceptual model. 


\section{Theoretical Framework and Hypotheses}

\subsection{Turnover}

Staff turnover is usually linked to a loss of knowledge, skills and abilities, and employees' social capital (relationships within and outside of the firm), in addition to costs associated with the recruitment, training and adaption of a new employee (cf. [14-16]). Consequently, collective (i.e., organization-level) turnover has been shown to be negatively related to organizational performance [17]. These costs of employee replacement vary among industries and position [14], and percentages have been mentioned ranging between $93 \%$ and $200 \%$ of the leaving employee's salary, depending on responsibilities and skills [18,19]. On the other hand, turnover does have its benefits. Newly hired employees may be better suited for the company and bring in new ideas and up-to-date skills [14,15,20]. Furthermore, turnover may serve as a constraint on labor wages, and the leaving of marginal performers can even be desirable [14].

What is clear is that turnover is an issue that has to be carefully managed and kept at appropriate levels [14]. In general, lower turnover rates are preferred to higher rates as a meta-analysis on the consequences of collective turnover clearly showed [21]. As such, HRM practices are perceived as an important way for organizations to manage it. Several studies investigated the impact of various HRM practices on turnover $[9,22,23]$ and practices which are meant to affect the antecedents of turnover: job satisfaction and organizational commitment [24]. The recent meta-analysis by Jiang et al. [6] indeed showed that high performance work practices are related to lower turnover. They reported averaged mean correlations between -0.17 and -0.19 for the relation between HR practices and voluntary turnover. This confirms the potential impact of HR practices, but also shows that HR practices alone are not the full story when it comes to explaining differences in high versus low turnover.

\subsection{Institutional Setting}

We would like to argue that for a thorough understand of collective turnover, incorporating the national context in terms of the institutional setting is essential. Research focusing on institutional determinants of managerial and organizational practices is comprehensive [10] and although there are different perspectives, they share the assumption that institutional factors structure and limit actions and interactions of managers and employees [10,25]. The national economies of different countries have a dissimilar legal context and different histories with respect to the relationship between employers and other relevant business stakeholders, such as shareholders and unions. We have seen that in most countries collective actors appeared that jointly defined a framework of complementary rules and habits to coordinate work relations and firm governance [25]. As such, this generally agreed upon way of collaboration and coordination may be a more important antecedent of management practices than factors like firm size, industry embeddedness or technology. Therefore, $\mathrm{n}$ order to maintain their legitimacy, firms will likely have to adjust their practices to the environment in which they operate, thus conforming to institutional pressures [26,27].

There is a growing awareness that varieties in the capitalism perspective influence the effectiveness of HRM practices [13,25,26]. These varieties describe the institutional environment of various national economies [27]. The underlying assumption is that a firm is relational. From this perspective, the firm is an actor that needs to cultivate its core competencies and capacities through relationships. In order to be successful, firms have to engage in efficient relationships with shareholders, employees and other firms [28]. Examples of such relationships include relationships with financial markets (e.g., rising funds), industrial relations (e.g., regulate wages and working conditions), inter-firm relations (e.g., securing access to inputs and technology) or firm-employee relations (e.g., securing the cooperation of workforce) [29].

Within the varieties-of-capitalism approach, the level of coordination is hereby perceived as the underlying dimension that differentiates economies [29]. To help us understand how coordination plays a role in distinguishing between variations of coordinating relations, two ideal types can be 
described. That is, liberal market economies (LMEs) where relations between firms and other actors are coordinated mainly through competitive markets (with USA as a typical example), and second, coordinated market economies (CMEs) where strategic interactions dominate (with Germany as a typical example) [29]. LMEs are coordinated mainly through competitive markets (arms-length relations, formal contracting), where equilibrium is dictated primarily by market signal and relative piracies; and CMWs are coordinated mainly through a process of strategic interaction similar to game theory, where reaching equilibrium depends on institutional support for information-sharing, monitoring, sanctioning and deliberation. Although both mechanisms are present in all capitalistic economies, the balance between them varies across political economies [29]. Differences in the level of coordination are visible in such things as bargaining over wages and working conditions. This mainly takes place at the company level with lots of room for individual variation, or at the country level where collective labor agreements become law, even for non-unionized companies. The labor markets in countries with economies that are less coordinated are also more fluid [28]. This has implications for the relationship between a company and the individual employee. In highly coordinated economies, training and development is more company and sector oriented, whereas in less coordinated economies, more general skills are being taught. A more fluid labor market may, as a result, be related to lower continuous commitment. This makes it likely that people will and can apply for another job if their present working conditions are not to their liking. Conversely, coordinated market economies provide employees with more job securities and less need to change jobs. Also, the more company-specific an employee's skills are, the more likely it is that this person will be committed to its present employer. This gives the first hypothesis:

- Hypothesis 1: A higher country-level coordination index is related to lower company-level employee turnover.

\subsection{Human Resources Management (HRM) Practices}

Within the HRM field, it is popular to combine practices into one or more bundles that jointly exercise their influence on engagement and performance. One approach is to combine all high performance practices into one bundle [30]. Others differentiate HR practices in two [13,31] or three [32] bundles. Our approach towards HRM practices builds on the work by Gooderham et al. [13], who, drawing on universalistic and configurational perspectives on HRM practices, distinguished between calculative HRM practices and collaborative HRM practices. This approach is also influenced by the contribution of Walton [33] on control versus commitment HRM. We believe that current insights linking HR practices to absenteeism [34] and collective turnover [21] justify a four-bundle division of $\mathrm{HR}$ bundles to achieve a broader, fuller understanding of the impact of HR on turnover. A differentiated view also allows for a more explicit inclusion of the well-being dimension, which was recently advocated as essential for the future of HR [35].

The first bundle is remunerative HR, which is the compensation practice that ensures that an employee's contribution is assessed and rewarded accordingly. It is part of the calculative practices of Gooderham et al. [13]. The second bundle, communicative HRM, is part of the Gooderham's et al. [13] collaborative HRM, which views employees as active partners that have an impact on firm performance and core assets, not least in terms of creativity and innovation. Gooderham et al. [13] proposed that integrating employees' interest can be achieved by an intensive communication of mission, vision and strategy, which is supported by an explicit communication policy.

The third bundle is developmental HR, which focuses on training and developmental practices, which may enhance employees' internal motivation because they help employees to become better at their job. This in contrast to the remunerative HR practices that focus on enhancing the external motivation of employees. Self-determination theory [36] suggests that work practices focused on external motivation may have a contrasting effect compared to work practices focused on internal motivation. According to their theory, a focus on external motivation can even lead to diminished engagement. The attention for training is part of the developmental perspective, which represents 
the focus on training, career paths, and competences. Jiang et al. [6] also placed such developmental practices together under the term motivation-enhancing HR practices.

Our fourth bundle is well-being HR, which was added to the model to represent those HR practices focused purely on the needs of the employee. As part of the psychological contract, employees may expect not only that an organization provides opportunities and resources to perform as well as possible in their jobs, but also to have practices in place focused on their well-being specifically [37]. Examples of such practices are attention to work stress and health, and allowing flexible work arrangements to achieve a better work-home balance.

This paper introduces a way to measure these four practices using an already existing survey. Although not specifically designed with our theoretical framework in mind, we aim to show with the questions available that a four-divisional perspective on HR practices can be confirmed empirically. Furthermore, in line with previous turnover research, we expect that all four HR practices will have a beneficial influence on turnover. Boon at all (2014) showed that a division into three HR bundles was relevant to predict absenteeism mediated by satisfaction. The meta-analysis by Heavy et al. [21] showed that a broad range of HR practices-such as benefits, dispute resolution, internal mobility, and pay-is related to less turnover. Following these earlier studies leads to the second hypothesis that consists of four parts:

- Hypothesis 2a: Remunerative HR practices are negatively related to collective turnover.

- Hypothesis $2 \mathrm{~b}$ : Communicative HR practices are negatively related to collective turnover.

- Hypothesis 2c: Developmental HR practices are negatively related to collective turnover.

- Hypothesis 2d: Well-being HR practices are negatively related to collective turnover.

\subsection{HRM Practices across Countries}

This study investigates the relationship between HRM practices and turnover in a cross-national setting, which makes the notion of HRM convergence across countries as a result of globalization an interesting notion. The study by Heavy et al. [21] already showed that the impact of HR practices on turnover-in strength and direction-differs. In our study, we propose that the institutional context in terms of the level of coordination is influencing this impact, such that the impact may be stronger for one practice than for some of the others. A more segregated view on HR bundles allows for a deeper insight into the influence of such differences. Brewster in his 1995 paper [38] argued for one "European model of HRM," yet he reviewed this claim in the paper from 2004, where he viewed the European model as more diverse and referred to a couple of studies which identified different clusters of European HRM [39]. Furthermore, Mayrhofer et al. [40] examined the use of HRM practices within the private sector from 13 European countries between 1992 and 2004, and although they did find that countries have become more alike in the way they manage people, there was no evidence for a final convergence. Gooderham and Nordhaug [8] also described Europe as a set of distinctive HRM regimes both in terms of culture and institutions; they argued that treating various countries as clusters may conceal significant differences that have an impact on both HRM and firm's performance. Thus, countries should be treated individually. Furthermore, the use of HRM practices was shown to vary significantly across the countries $[9,25,26]$. Remunerative HRM practices are more popular in USA, while the developmental approach is more common in Europe [25]. In this paper, we will focus on two ways that countries may differ. One is in the actual use of HR practices for which we expect differences between countries in line with the above-mentioned studies, and the second is turnover, through a country's institutional determinants. We build on earlier research that showed that remunerative practices are more popular in LMEs $[10,25,26]$ and developmental practices are more popular in CMEs [26].

Furthermore, Rizow and Croucher [9] found that in CMEs, the negative relationship between the collaborative HRM practices and turnover is the strongest, and that calculative HRM practices were positively related to turnover (the use of calculative practices was related to higher turnover) in a 
couple of CME countries. Thus the impact of HRM practices may be influenced by the institutional setting. In general, we expect that the effectiveness of HRM practices is strengthened if it is in line with the institutional practice of a country. This supports Rizow and Croucher [9] who view HR practices as instruments to enhance the link between the labor market and companies' need for good personnel. With a different institutional context, other HR practices are more efficient. Within LME countries, the social contract between employee and company is stronger based on social exchange. Therefore, HR practices focused on remuneration and on communication fit better within LME given their strong focus on individual performance and results. Conversely, focusing on the social contract in terms of remuneration and communication can backfire in countries in CME countries. However, developmental and well-being HR practices address more universal human needs, address the company as a collective, and are more committed to building a relationship based on trust, respect and caring. In organizations where there is high trust and respect, employees will have a stronger willingness to stay committed to this company [41]. As such, these are expected to be beneficial for a lower level of turnover, independent of the coordination index. Thus the following hypotheses have been formulated:

- Hypothesis 3a: The relationship between remunerative HR practices and collective turnover is negatively influenced by the coordination index, such that in countries with more coordination this relationship becomes stronger.

- Hypothesis 3b: The relationship between communication HR practices and collective turnover is negatively influenced by the coordination index, such that in countries with more coordination this relationship becomes stronger.

- Hypothesis 4a: The relationship between developmental HR practices and turnover will not be influenced by the coordination index.

- Hypothesis $4 \mathrm{~b}$ : The relationship between well-being HR practices and turnover will not be influenced by the coordination index.

\section{Sample and Methods}

\subsection{Sample}

The sample consists of 830 companies who all participated with the Top Employers Institute's Top Employer Award survey in 2010, 2011, or 2012. There was a total of 85 companies from The Netherlands, 67 from Belgium, 97 from the United Kingdom, 19 from Brazil, 33 from Switzerland, 47 from China, 59 from France, 51 from Italy, 42 from Poland, 229 from Germany, 41 from South Africa, and 60 from Spain. The companies were active in different industries: automotive $(8.8 \%)$, banking $(5.2 \%)$, chemicals $(4.5 \%)$, consumer goods and services $(8.2 \%)$, construction $(2.7 \%)$, electronics $(5.80 \%)$, energy $(6.5 \%)$, engineering $(6.7 \%)$, financial services $(4.7 \%)$, food and beverage $(4.6 \%)$, healthcare $(4.2 \%)$, insurance $(2.9 \%)$, IT (11.6\%), manufacturing (4.5\%), media/advertising $(2.1 \%)$, mining $(0.6 \%)$, pharmaceuticals $(4.7 \%)$, professional services $(5.4 \%)$, public sector $(1.7 \%)$, real estate $(0.4 \%)$, recruitment $(1.1 \%)$, retail $(4.1 \%)$, telecommunications $(6.2 \%)$, transport and logistics $(2.3 \%)$, utilities $(2.2 \%)$ and an "other" category for industries that did not fit into any of the above (31.5\%). When companies participated over several years, only the survey from the first year was included.

The average number of company employees within a country was $5670(\mathrm{SD}=16,610)$, which ranged between 14 and 248,637. The majority of the sample (656 companies, $79.0 \%$ ) was part of a multi-national entity; the remaining 174 companies were nationally based, mainly from The Netherlands (29), Belgium (17), China (13), Germany (33), Poland (12), United Kingdom (31), and South Africa (11). The survey was filled out by the HR manager. 


\subsection{Measures}

\subsubsection{HRM Practices}

The four HRM bundles were measured by different items taken from the CRF institute survey (for more information on the CRF institute certification process, see http:/ / www.top-employers.com/ how-it-works /Certification-process). The answering format differed between the questions for two bundles; for developmental HR and well-being HR, a two-step approach was used instead. First, the scores of the separate sub-dimensions were calculated. This was the input for the confirmatory factor analysis. For the overall score, the scores of the sub-dimensions were standardized and averaged into one overall score for each bundle. This was the input for the multilevel regression analysis.

For remunerative HR, companies were asked for the percentage of employees' remuneration that was linked to individual, group and/or organizational performance for the following groups: executives, management, professionals, and support staff. Cronbach's Alpha for this four-item scale is 0.86 .

For communication HR, companies had to indicate how frequently the organization's mission, vision and values were communicated through the following channels: executive management visits to offices/branches, staff meetings, email, and intranet. In addition, for the same channels as above, the frequency that the organization's results were communicated to employees. The answering format was a four-point Likert scale ranging from "not used" to ">2 times a year." Cronbach's Alpha for this eight-item scale is 0.80 .

Developmental HR was measured in four aspects. First, companies had to indicate for which job-level clear career paths were defined (true/false): executive level, management level, and professional level. Cronbach's alpha is 0.68. Second, insight into the competence levels of key employees (management and professionals) is checked with three questions (true/false) on medium-term, strategic forecast of organizational competency needs, the existence of a GAP analysis between current future competency needs, and implementation of action plans to deal with future competency needs. Cronbach's alpha is 0.67. Third, companies indicated which of the following development programs are available to employees: internship, traineeships, talent management, leadership development, coaching/mentoring, peer support, job rotation, general training, job-related training, individually selected training, and international exchange programs. Answering scale ranged from 0-"not available," 1-“present and utilized," to 2-“present, utilized and formally defined in HR policy." Cronbach's alpha is 0.74 . Fourth, companies were asked to which extent the following top performers' practices were in place: identifying top performers, close monitoring of top performers, employee performance plans, tracking system for development plans, and career transition program. Answering scale ranged from 0- "not available," 1-“"present and utilized," to 2- "present, utilized and formally defined in HR policy." Cronbach's alpha is 0.71 . The scores of the four subscales were standardized and averaged into one overall score. Cronbach's alpha of this combined scale is 0.70.

Well-being HR was measured in two aspects. First, companies indicated which of the following well-being programs they offered to their employees: stress management, time management, ergonomic support, personal support line, employee debt support, burnout recovery program, confidential advisor, maintenance of salary level above legal requirement during illness, and maintenance of employee contractual rights above legal requirements during illness. Answering format ranged from 0-“"not available," 1-“present but not defined in HR policy," 2-"formally defined in HR policy and available for all employees." Cronbach's alpha is 0.78. Second, the extent to which the following flexible work arrangements are offered to employees: compressed work hours, flexi-time work, job-sharing, part-time work, sabbatical break, self-rostering, term-time work, telecommuting, special parents' leave. Answering format ranged from 0_ “not available," 1—“"present but not defined in HR policy," 2-"formally defined in HR policy and available for all employees." Cronbach's alpha is 0.70 . 


\subsubsection{Turnover}

Companies had to indicate the percentage of staff leaving the organization in a year with the following question: "What was your annual staff turnover (voluntary + involuntary) in the last financial year?" Similar to other studies on collective turnover, staff turnover was defined in the survey as the percentage of the total workforce leaving the organization in a year. Given the skewedness of the turnover data and to normalize the distribution of this variable, the square root was taken as input for the analysis.

\subsubsection{Coordination Index}

In order to measure the level of coordination within a country, Hall and Gingerich [29] developed a yardstick they called the coordination index. This index allows for a direct comparison of institutional settings between countries. The original coordination index of Hall and Gingerich [28,29] was based on data from the 1990s. It included the following variables, with brackets marking the year from which the data originated: shareholder power (1998), Dispersion of control (1995), size of stock market (1993), level of wage co-coordination (1991), degree of wage coordination (1994), and relative percentage of people holding their jobs less than a year at country level (1997). Their work provides an index of 20 countries, excluding emerging economies like China, Brazil and South Africa (which are part of our database). To bring the index up to date and broaden the number of countries, we calculated a new index using data that are more current in a similar way. Combining the sources described below, a full database of 37 countries becomes available.

To come as close as possible to the format used by Hall and Gingerich [28], we searched for publicly available databases that together give an indication of the coordination in corporate government and in labor relations. We were able to find five indicators in the literature based on two sources, that is Djankov et al.'s [42] paper on the self-dealing index and data made available through the database on Institutional Characteristics of Trade Unions, Wage Settings, State Intervention and Social Pacts, 1960-2010 (ICTWSS, [43]). Djankov et al.'s [42] provided the anti-self-dealing index that provides insight into shareholder power. It was developed to give an indication of the legal protection of minority shareholders against expropriation by corporate insiders. From the ICTWSS database, we included four indicators, that is Coordination of Wage Bargaining which could differentiate between 5-“economy-wide bargaining" to 1-“fragmented bargaining, mostly at company level"; the dominant level(s) at which wage bargaining takes place, ranging between 5-“"national or central level" and 1- "local or company level"; the level of government intervention in wage bargaining, ranging between 1-“none" to 5-"government imposes wage settlements and a ceiling on bargaining outcomes"; the mandatory extension of collective agreements by public law to non-organized firms, ranging between 0-"not available" to 2-"available and affecting a significant share of the workforce." From the ICTWSS database, the latest data was included (2010 in most cases, 2008 in two others). All five indicators were first standardized and then averaged into one coordination index. The internal consistency (Cronbachs's alpha) of this scale is 0.71 . For comparison reasons to previous studies, the average score was transformed to a score between 0 and 1.

To check the validity of this new coordination scale, we correlated it with the original score of Hall and Gingerich [28] for the 20 countries in their study. The intercorrelation was 0.79. This relatively high correlation indicates that together our proxy indicators draw upon processes similar to the original, especially if we take into consideration that more than 15 years have passed between the measurement of the indicators that were part of the original index and the indicators used for our new index. The discriminant validity with respect to Hofstede's six cultural dimensions was shown; only uncertainty avoidance was significantly correlated $(r=0.49)$. See Table 1 for the coordination scores of the countries included in the current study. The full table of all 37 countries is available in Table A1. 
Table 1. Coordination Index and Human Resources Management (HRM) Practices across Countries.

\begin{tabular}{|c|c|c|c|c|c|c|c|c|c|c|}
\hline & \multirow[b]{2}{*}{$n$} & \multirow[b]{2}{*}{ CI } & \multicolumn{2}{|c|}{$\begin{array}{c}\text { Remunerative } \\
\text { HR }\end{array}$} & \multicolumn{2}{|c|}{$\begin{array}{c}\text { Communication } \\
\text { HR }\end{array}$} & \multicolumn{2}{|c|}{$\begin{array}{c}\text { Developmental } \\
\text { HR }\end{array}$} & \multicolumn{2}{|c|}{$\begin{array}{c}\text { Well-Being } \\
\text { HR }\end{array}$} \\
\hline & & & $M$ & $S D$ & $M$ & $S D$ & $M$ & $S D$ & $M$ & $S D$ \\
\hline United Kingdom & 97 & 0.00 & 20.16 & 13.78 & 2.28 & 0.53 & -0.01 & 0.69 & 0.39 & 0.79 \\
\hline Poland & 42 & 0.32 & 17.72 & 7.86 & 2.24 & 0.28 & -0.01 & 0.59 & -0.58 & 0.62 \\
\hline Switzerland & 33 & 0.38 & 19.16 & 16.09 & 2.15 & 0.37 & -0.10 & 0.84 & 0.24 & 0.96 \\
\hline Italy & 51 & 0.47 & 18.31 & 7.12 & 2.25 & 0.39 & 0.21 & 0.52 & -0.68 & 0.68 \\
\hline China & 47 & 0.57 & 22.53 & 10.93 & 2.33 & 0.56 & 0.58 & 0.60 & -0.62 & 0.71 \\
\hline France & 59 & 0.60 & 15.31 & 7.67 & 2.26 & 0.47 & -0.06 & 0.69 & -0.47 & 0.66 \\
\hline South Africa & 41 & 0.62 & 29.38 & 26.74 & 2.43 & 0.63 & -0.12 & 0.65 & -0.22 & 0.84 \\
\hline Germany & 229 & 0.68 & 18.20 & 11.30 & 2.13 & 0.37 & -0.10 & 0.78 & 0.19 & 0.83 \\
\hline Brazil & 19 & 0.69 & 17.53 & 7.24 & 2.29 & 0.45 & -0.05 & .62 & -0.80 & 0.77 \\
\hline The Netherlands & 85 & 0.69 & 14.08 & 8.75 & 2.20 & 0.40 & -0.11 & 0.70 & 0.51 & 0.66 \\
\hline Spain & 60 & 0.81 & 19.41 & 9.42 & 2.36 & 0.58 & 0.28 & 0.58 & -0.17 & 0.76 \\
\hline Belgium & 67 & 0.91 & 12.41 & 7.24 & 2.23 & 0.37 & 0.00 & 0.67 & 0.20 & 0.60 \\
\hline $\mathrm{F}(11,818)$ & & & \multicolumn{2}{|c|}{$6.934^{* * *}$} & \multicolumn{2}{|c|}{$2.959 * * *$} & \multicolumn{2}{|c|}{$5.005^{* * *}$} & \multicolumn{2}{|c|}{$21.533^{* * *}$} \\
\hline
\end{tabular}

Notes: $\mathrm{CI}=$ Coordination index, range between 0 and $1 ;{ }^{* * *} p<0.001$.

\subsection{Analysis}

The HRM practices and the turnover rate are measured at company level. The correlations of the variables at company level are described in Table 2. The coordination index is a country-level variable. To acknowledge the multilevel structure, the R syntax provided by Aguinis et al. [44] was used to test the hypotheses. The HRM practices were centered within countries. This method allows for a more accurate estimate of the influence of the country-level variables on the company-level variables. Similarly, this is the recommended practice for testing cross-level moderating effects [45].

Table 2. Correlations between Study Variables at Company Level $(n=830)$.

\begin{tabular}{llcccccc}
\hline \multicolumn{1}{c}{ Study Variables } & $\boldsymbol{M}$ & $\boldsymbol{S D}$ & $\mathbf{1}$ & $\mathbf{2}$ & $\mathbf{3}$ & $\mathbf{4}$ \\
\hline 1. & HRM Remunerative practices & 18.23 & 12.30 & & & & \\
2. & HRM Communication practices & 2.23 & 0.44 & -0.05 & & & \\
3. & HRM Developmental practices & 0.01 & 0.71 & $0.11^{* *}$ & 0.02 & & \\
4. & HRM Well-being practices & -0.17 & 0.76 & -0.01 & -0.04 & $0.28^{* * *}$ & \\
5. & Collective Turnover & 2.90 & 1.43 & $0.09^{*}$ & 0.04 & $-0.08^{*}$ & $-0.16^{* * *}$
\end{tabular}

Notes: Please note that the four HR practices were calculated differently and that the value for turnover was the square root of the actual turnover percentage; ${ }^{* * *} p<0.001,{ }^{* *} p<0.01,{ }^{*} p<0.05$.

\section{Results}

\subsection{Factorial Validity of the HRM Practices Dimensions}

Using confirmatory factor analysis, the underlying presupposed four-bundle structure of the HRM practices was tested. Mplus 6.21 [46] was used whereby the cluster option indicated the country where a company was based to control for variance due to the multilevel structure of companies within countries which may influence the error variances. Within Mplus, it is also possible to indicate which items are categorical, which was done for all dichotomous items and for the items with a three-point answering scale. Remunerative HRM was measured directly with the four items as was communication HRM with eight items. Developmental HRM was a second-order factor with the four practices as first-order practices indicated by the individual items. Well-being HRM was similar as a second-order factor with the two practices as first-order practices indicated by the individual items. The model fit was already acceptable $(\mathrm{X} 2(1262)=1468.455, p<0.001, \mathrm{CFI}=0.91$, TLI $=0.90$, RSMEA $=0.02)$. Modification indices showed that there was residual variance between the two well-being practices focused on companies doing more than what was legally required of them. These practices were allowed to correlate; the adjusted model had a satisfactory fit to the data $(\mathrm{X} 2(1261)=1447.298, p<0.001$, 
$\mathrm{CFI}=0.92, \mathrm{TLI}=0.91, \mathrm{RSMEA}=0.02$ ), thus confirming the presupposed underlying four-bundle structure of HRM practices.

The standardized solution of this model showed that indicators of Remunerative HRM ranged between 0.62 and 0.96; for communication HRM, the range was between 0.34 and 0.64; for developmental HRM, the four practices loaded between 0.49 and 0.79; and for well-being HRM, the indicators were 0.66 and 0.99 . The correlations in Table 2 confirm that the four HRM dimensions are independent constructs, ranging between 0.01 and 0.28 .

\subsection{HRM Practices across Countries}

Table 1 shows the average values of the four HR practices in the 12 countries in our sample. The countries are arranged based on coordination index from low (United Kingdom) to high (Belgium). An ANOVA showed that for all four HR practices these averages are significantly different between the countries. We used a Scheffe post hoc test to help us interpret these differences. The Scheffe test calculates the possibility of underlying subsets that combine countries with similar scores. This helps with the interpretation of the results.

For remunerative HR practices, the lowest values were found for Belgium and the highest for South Africa. The Scheffe test suggested two homogeneous subsets. South Africa was the only country that was only part of the second subset. Switzerland, Spain, China and the United Kingdom are part of both, and the remaining countries were only part of the first subset. Therefore, for remunerative practices, we can conclude that it was especially South Africa that stood out in terms of especially high remunerative HR practices. Low on remunerative practices are Belgium, The Netherlands, France, Italy and Germany.

For communication HR practices, although the differences between the countries were significant, only one subset was found. This suggests that across countries the similarities are larger than the differences. Communication practices are generally used, only slightly influenced by country.

For developmental HR practices, the Scheffe test gave two subsets. Now, it was China that was placed in one set only, scoring relatively high. Spain, Italy, Belgium, the United Kingdom, Poland and Brazil were placed in both subsets. Relative less attention to developmental practices was given in France, South Africa, The Netherlands, and Switzerland.

For well-being HR practices, the Scheffe test gave four subtests. These HR practices seem to differ most between countries. The countries with the lowest values that were placed together were Brazil, Italy, China, Poland, France, South Africa, and Spain. The countries with the highest values were The Netherlands, United Kingdom, Switzerland, Belgium, Germany and Spain. The Netherlands was the only country that was placed in the highest subset. Spain seems to take up the middle ground.

\subsection{HRM Practices and Turnover}

The relation between HRM practices and turnover was studied in four steps, following the recommendations of Aguinis et al. [43], Table 3: (1) Null model; (2) Random intercept and fix slope model; (3) Random intercept and random slope model, and (4) Cross-level interaction model. Beforehand, we tested the possible influence of being part of a multinational company and of cultural distance on turnover intention. Cultural distance was calculated according to the guidelines of Kogut and Singh [47], based on the current six dimensions formulated by Hofstede et al. [48]. Neither being part of multinational corporation nor cultural distance was significantly related to collective turnover; estimates were $-0.09(p=0.41), 0.097$ and $0.117(p=0.26)$, respectively. As recommended by Becker [49], we excluded these control variables in a subsequent analysis given that they were not significantly related to the dependent variables. 
Table 3. Cross-Level Interaction of HR Practices and Coordination Index on Collective Turnover.

\begin{tabular}{|c|c|c|c|c|}
\hline \multirow{2}{*}{ Level and Variable } & \multicolumn{4}{|c|}{ Model } \\
\hline & I & II & III & IV \\
\hline \multicolumn{5}{|l|}{ Level 1} \\
\hline Intercept & $2.976^{* * *}(0.122)$ & $3.681^{* * *}(0.211)$ & $3.765^{* * *}(0.125)$ & $3.574^{* * *}(0.258)$ \\
\hline \multicolumn{5}{|l|}{ HRM } \\
\hline Remunerative practices & & $0.009 *(0.004)$ & $0.009 *(0.004)$ & $0.001(0.005)$ \\
\hline Communication practices & & $0.096(0.107)$ & $0.096(0.107)$ & $0.038(0.145)$ \\
\hline Developmental practices & & $-0.039(0.073)$ & $-0.039(0.073)$ & $-0.029(0.112)$ \\
\hline Well-being practices & & $-0.368 * *(0.067)$ & $-0.368 * *(0.067)$ & $-0.338^{* *}(0.100)$ \\
\hline \multicolumn{5}{|l|}{ Level 2} \\
\hline Coordination index & & $-1.266 * *(0.345)$ & $-1.431^{* *}(0.260)$ & $-0.961(0.538)$ \\
\hline $\begin{array}{l}\text { CoordinationHL } \\
\text { (dummy) }\end{array}$ & & & & $-0.123(0.246)$ \\
\hline \multicolumn{5}{|l|}{ Cross-level interactions } \\
\hline CoordHL $\times$ Remunerative & & & & $0.018 *(0.008)$ \\
\hline CoordHL $\times$ Communication & & & & $0.110(0.214)$ \\
\hline CoordHL $\times$ Development & & & & $-0.020(0.149)$ \\
\hline CoordHL $\times$ Well-being & & & & $-0.045(0.134)$ \\
\hline \multicolumn{5}{|l|}{ Variance components } \\
\hline Within country & 1.859 & 1.764 & 1.765 & 1.751 \\
\hline Intercept & 0.143 & 0.053 & 0.000 & 0.085 \\
\hline Slope & & & 0.181 & 0.018 \\
\hline Intercept/slope & & & 0.000 & -0.039 \\
\hline -2log likelihood (FIML) & 1.445 & 1.442 & 1.420 & 1.416 \\
\hline Pseudo $\mathrm{R}^{2}$ & & 0.11 & 0.11 & 0.11 \\
\hline
\end{tabular}

The null model allows for the calculation of the ICC index of turnover, which was 0.07. Although only modest in absolute terms, this value is high enough to warrant our multilevel analysis. Models 2 and 3 show that a higher coordination index is related to lower turnover. From the four HR bundles, the HR remunerative practices category is related to more turnover, and HR well-being to less turnover. No extra variance was explained with the remaining two HR practices.

To check for the cross-level interaction, we created a dummy variable out of the coordination index using a median split. This variable was 1 for Germany, Brazil, The Netherlands, Belgium, and Spain $(n=442)$ and 0 for the United Kingdom, Poland, Switzerland, Italy, China, France and South Africa $(n=388)$. We chose this strategy to avoid making a type 2 error, reporting no relationship where one does exist. Mathieu et al. [50] showed that the power of detecting cross-level interactions diminishes considerably with low numbers on level 2 . With only 12 countries in our sample, we would have needed an extremely strong effect to reach significance. With a dummy variable, we were able to test the differentiated influence of high versus low coordination with more power. We kept the main effect of the coordination index in the equation to make sure that we would report a cross-level interaction only if it proved to be significant after controlling for the main effect. Model 4 shows that of the four possible interactions, one was indeed significant: remunerative HR practices. Figure 2 helps with the interpretation of that interaction. The figure shows that the positive influence of remunerative HR practices on turnover (i.e., more turnover) takes place in countries with a high coordination index and not within countries with a low coordination index. 


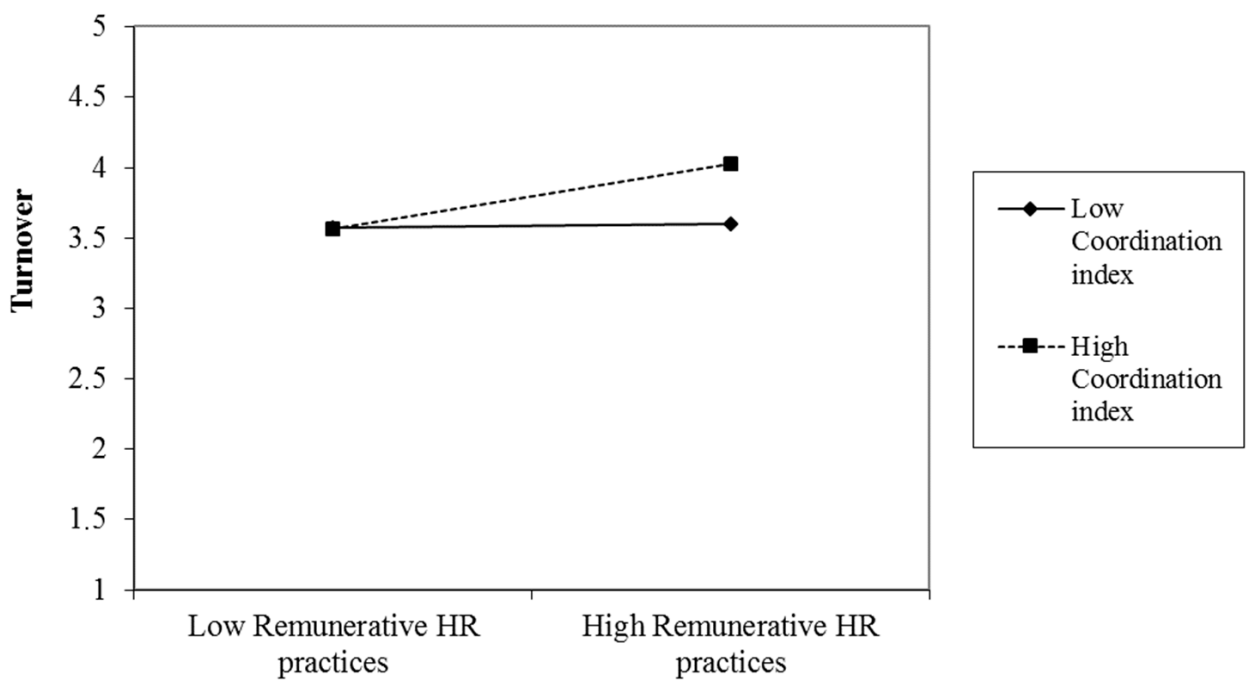

Figure 2. Interaction of country coordination index with company HR remunerative practices on collective turnover.

\section{Discussion}

The study reported in this article set out to provide a more thorough insight into the combined influence on collective turnover of company HR practices and the institutional determinants within a country. Based on a dataset of 830 companies from 12 countries including European and emerging economies, four main contributions can be distinguished. First, we showed that employee turnover is related to both country institutional determinants and to company HR practices; second, we argued and showed that within an international context, a four-bundle division of HR practices makes sense theoretically and practically; third, remunerative HR practices may have a positive influence on turnover, particularly within countries high in coordination; fourth, independent of the institutional setting, HR well-being practices are the most beneficial practices a company can incorporate when it aims to reduce employee turnover.

Our first contribution is that we confirm that it is crucial to take into account the institutional context of companies. Turnover is clearly influenced by factors outside the organization. It helps explain the relatively low relationships between HR practices and voluntary turnover in Jiang et al.'s [6] meta-analysis. Notwithstanding recent evidence of the potential influence of culture on the impact of HR practices [51], we show that when taking into account a full-breadth perspective on HR practices, the institutional distance may be of more importance. We introduce in this paper a coordination index developed specifically for this study. Building on Hall and Gingerich's [28,29] work, this coordination index extends the original index and allows for studying the institutional distance between 37 countries (instead of only 20), including the emerging economies; it is also based on more recent data. The availability of this extended and updated index (see Table A1) may encourage more international research like ours and that of Brookes et al. [25].

The second contribution to the HRM literature is that we suggest a broader differentiation of HR practices than is being used at present. At present, HR practices are either differentiated into one [52], two [13] or three bundles [6]. The here-suggested differentiation into four bundles builds on these earlier frameworks but takes a different approach to define the bundles. The most important contribution is that we explicitly define well-being practices as an essential element of HR practices that deserves separate attention. This takes our perspective on high commitment HR one step further than, for example, the study of Hauff et al. [53] who also confirmed the potential beneficial influence of high commitment HRM operationalized in a more traditional way. This HR well-being bundle has clearly been neglected in previous research for its role of in collective turnover, as is exemplified by its not being included in Heavey et al.'s recent meta-analysis [21]. Although this aspect of HR 
may not be directly linked to organizational or personal performance, it is very likely to be indirectly relevant. Well-being practices are in place primarily for the employees themselves. They focus mainly on helping employees deal with things like stress, burnout, and achieving a good work-home balance, all of which in turn influence employee productivity [35].

Third, our operationalization of remunerative practices is directly related to Gooderham et al.'s [13] calculative practices. Our focus on performance rewards exclusively allows for a much clearer insight into its potential influence. Our results showed that incorporating HR remunerative practices into organizational practices may come with a price in terms of employee turnover, especially within countries that have a more coordinated economy.

Fourth, we showed that well-being HR practices are very important for an organization that aims to diminish turnover. This by itself should not come as surprise given the direct link between employee job satisfaction and turnover [54]; it does, however, emphasize that HR professionals should not forget this essential part of their role within organizations. Given the current emphasis on the strategic role of HR with its focus on the board level within organizations, it may be wise to keep remembering the crucial influence these practices have on the employee at the shop floor.

A study like ours has of course its limitations and strengths. The most important limitation is that we had to work with a survey not specifically designed to test the four bundles that we presupposed. However, the topics in the survey were broad enough to be able to measure most of them in a reliable and valid way. Although the internal reliability of two of the developmental HR subscales was below the ideal value of 0.70 , this is probably due to the categorical nature of the underlying items. Its influence also is probably minimal because the overall score of developmental $\mathrm{HR}$ was calculated averaging four subdimensions. The internal consistency of these four subscales was 0.70 . Another limitation is that the total number of countries was limited to 12. This reduced the power of our analysis and may lead to lower error variances at the country level [55]. However, this influence is partly countered by the large overall sample size of 830 companies and the high number of companies within the different countries, ranging between 19 and 229 companies. In this respect, the relative low ICC score may work to our advantage [56]. As a consequence of the limited number of countries, we had to use a dummy variable based on median-split to test the interaction hypotheses. As such, we lost insight into country variance by actually testing two clusters. Another limitation is that the turnover data were provided by the HR professionals and not directly from the company records. However, it should be acknowledged that the CRF institute has a check built into their data collection to ensure the reliability of the data. A strong point of our study is that we were able to include emerging economies in our analysis which broadens the generalization of our findings. Lastly, we focused on the institutional setting instead of on national cultural differences, following earlier evidence presented by Gerhart [57] showing the limited influence of culture. The recent study by Peretz et al. [51] did show the specific moderating influence of culture on the effectiveness of diversity, confirming its influence for specific HR practices. In our study, cultural distance was incorporated as a potential influence. However, there was no influence of cultural distance on collective turnover within our sample.

\section{Practical Implications and Conclusions}

Our study has several practical implications. Multi-national corporations that originate in a country low in coordination should be careful with implementing remunerative practices that work well in their own country into countries high on coordination. It is likely that this might backfire. Furthermore, the results clearly support a stronger implementation of well-being practices in terms of stress management, personal support, flexible work arrangements and parental leave. Although these practices are not directly related to individual performance, they are supporting the general sense of care by the company, thereby enhancing the psychological contract between company and employee. This is likely to result in a stronger commitment, as is shown here in lower turnover. The results also show that even in our world of global connections and stronger interconnections between countries, the national context is still a very influential factor. This is even the case within 
Europe where the European Union aims to create a single economic market. Human resources (HR) practitioners are encouraged to look beyond the cultural practices and values and take explicit note of the institutional setting.

In conclusion, our study adds to our knowledge of the relation between HR practices and turnover from an international perspective. It complements the empirical knowledge on the effectiveness of human resources management (HRM) practices in a cross-national setting and supports the notion that the institutional context should be given more attention when trying to understand crucial aspects related to HR effectiveness. HR management theory is still very much influenced by the practice within the USA; our study suggests that such practices may backfire within more coordinated economies. Future HR studies would be useful with more companies from a broader range of emerging economies and with a theoretical framework that takes the international institutional context into account.

Author Contributions: The original survey was developed and the data was collected at the Top Employers Institute by Arthur Lankester and Hans Rothweiler. The analyses and the development of the current measures was carried out by the Dirk van Dierendonck and Maria Zmyslona. The final write-up of this article and conceptual development was done by Dirk van Dierendonck.

Conflicts of Interest: The authors declare no conflict of interest.

\section{Appendix A}

Table A1. The Coordination Index (CI) of the 37 Countries in the Database.

\begin{tabular}{cccc}
\hline Country & CI & Country & CI \\
\hline Greece & 1.00 & Korea & 0.47 \\
Belgium & 0.91 & Slovakia & 0.46 \\
Spain & 0.81 & Bulgaria & 0.43 \\
Norway & 0.70 & Australia & 0.40 \\
Austria & 0.70 & Denmark & 0.39 \\
Brazil & 0.69 & Switzerland & 0.38 \\
Netherlands & 0.69 & Lithuania & 0.37 \\
Finland & 0.68 & Poland & 0.32 \\
Germany & 0.68 & Latvia & 0.31 \\
Hungary & 0.66 & India & 0.29 \\
Portugal & 0.64 & Indonesia & 0.26 \\
Luxembourg & 0.63 & Israel & 0.26 \\
South Africa & 0.62 & Japan & 0.23 \\
France & 0.60 & Ireland & 0.22 \\
Romania & 0.57 & New Zealand & 0.19 \\
China & 0.57 & Canada & 0.06 \\
Czech Republic & 0.53 & United States & 0.05 \\
Sweden & 0.51 & United Kingdom & 0.00 \\
Italy & 0.47 & & \\
\hline
\end{tabular}

\section{References}

1. Dess, G.; Lumpkin, G.; Eisnes, A. Strategic Management: Text and Cases, 4th ed.; McGraw-Hill: New York, NY, USA, 2009.

2. Hitt, M.A.; Bierman, L.; Shimizu, K.; Kochlar, R. Direct and moderating effects of human capital on strategy and performance in professional service firms: A resource based perspective. Acad. Manag. J. 2001, 44, 13-28. [CrossRef]

3. Hatch, N.; Dyer, J. Human Capital and Learning as a Source of Sustainable Competitive Advantage; Oxford University Press: Oxford, UK, 2004.

4. Hancock, J.I.; Allen, D.G.; Bosco, F.A.; McDaniel, K.R.; Pierce, C.A. Meta-analytic review of employee turnover as a predictor of firm performance. J. Manag. 2013, 39, 573-603. [CrossRef] 
5. Kepes, S.; Delery, J.E. HRM systems and the problem of internal fit. In The Oxford Handbook of Human Resource Management; Oxford University Press: Oxford, UK, 2007; pp. 385-404.

6. Jiang, K.; Lepak, D.P.; Hu, J.; Baer, J.C. How does human resource management influence organizational outcomes? A meta-analytic investigation of mediating mechanisms. Acad. Manag. J. 2012, 55, 1264-1294. [CrossRef]

7. Nyberg, A.J.; Ployhart, R.E. Context-emergent turnover (CET) theory: A theory of collective turnover. Acad. Manag. Rev. 2013, 38, 109-131. [CrossRef]

8. Gooderham, P.N.; Nordhaug, O. One European model of HRM? Cranet empirical contributions. Hum. Resour. Manag. Rev. 2010, 21, 27-36. [CrossRef]

9. Rizov, M.; Croucher, R. Human resource management and performance in European firms. Camb. J. Econ. 2009, 33, 253-272. [CrossRef]

10. Gooderham, P.N.; Nordhaug, O.; Ringdal, K. National embeddedness and calculative human resource management in US subsidiaries in Europe and Australia. Hum. Relat. 2006, 59, 1491-1513. [CrossRef]

11. Farndale, E.; Paauwe, J.; Morris, S.; Stahl, G.; Stiles, P.; Trevor, J.; Wright, P. Context-bound configurations of corporate HR functions in multinational corporations. Hum. Resour. Manag. 2010, 49, 45-66. [CrossRef]

12. Boselie, P.; Dietz, G.; Boon, C. Commonalities and contradictions in HRM and performance research. Hum. Resour. Manag. J. 2005, 15, 67-94. [CrossRef]

13. Gooderham, P.N.; Nordhaug, O.; Ringdal, K. Institutional and rational determinants of organizational practices: Human resource management in European Firms. Admin. Sci. Q. 1999, 44, 507-531. [CrossRef]

14. Eberly, M.B.; Holtom, B.C.; Lee, T.W.; Mitchell, T.R. Control turnover by understanding its causes. In Handbook of Principles of Organizational Behavior; Locke, E.A., Ed.; John Willey and Sons: West Sussex, UK, 2009; pp. 123-142.

15. Abbott, J.; De Cieri, H.; Iverson, R. Costing turnover: implications of work/family conflict at the management level. Asia Pac. J. Hum. Resour. 1998, 36, 25-43. [CrossRef]

16. Shaw, J.D.; Duffy, M.K.; Johnson, J.L.; Lockhart, D.E. Turnover, Social Capital Losses, and Performance. Acad. Manag. J. 2005, 48, 594-606. [CrossRef]

17. Park, T.-Y.; Shaw, J.D. Turnover rates and organizational performance: A meta-analysis. J. Appl. Psychol. 2013, 98, 268-309. [CrossRef] [PubMed]

18. Deery, M.A.; Iverson, R.D. Enhancing productivity: intervention strategies for employee turnover. In Productivity Management in Hospitality and Tourism; Johns, N., Ed.; Cassell: London, UK, 1996; pp. 88-95.

19. Johnson, A.A. The business case for work-family programs. J. Acc. 1995, 180, 53-58.

20. Cappelli, P. A market-driven approach to retaining talent. Harv. Bus. Rev. 2000, 78, 103-111.

21. Heavey, A.L.; Holwerda, J.A.; Hausknecht, J.P. Causes and consequences of collective turnover: A meta-analytic review. J. Appl. Psychol. 2013, 98, 412-453. [CrossRef] [PubMed]

22. Arthur, J.B. Effects of human resource systems on manufacturing performance and turnover. Acad. Manag. J. 1994, 37, 670-687. [CrossRef]

23. Huselid, M. The impact of human resource management practices on turnover, productivity, and corporate financial performance. Acad. Manag. J. 1995, 38, 635-672. [CrossRef]

24. Griffeth, R.; Hom, P.; Gaertner, S. A meta-analysis of the antecedents and correlates of employee turnover: Update, moderator tests, and research implications for the next millennium. J. Manag. 2000, 26, 463-488. [CrossRef]

25. Brookes, M.; Croucher, R.; Fenton-O-Creevy, M.; Gooderham, P. Measuring competing explanations of human resource management practices through the Cranet survey: Cultural versus institutional explanations. Hum. Resour. Manag. Rev. 2011, 21, 68-79. [CrossRef]

26. Poutsma, E.; Lighthart, P.E.M.; Veersma, U. The diffusion of calculative and collaborative HRM practices in European Firms. Ind. Relat. 2006, 45, 513-546. [CrossRef]

27. Soskice, D.; Hall, P. Varieties of Capitalism: The Institutional Foundations of Comparative; Oxford University Press: Oxford, UK, 2001.

28. Hall, P.A.; Gingerich, D.W. Varieties of capitalism and institutional complementarities in the political economy: An empirical analysis. Br. J. Political Sci. 2009, 39, 449-482. [CrossRef] 
29. Hall, P.A.; Gingerich, D.W. Varieties of Capitalism and Institutional Completementarities in the Macro-Economy; MPIfG Discussion Paper 04/5; Max Planck Institute fur Gesellschaftsforschung: Berlin, Germany, 2004.

30. Boselie, P.; Dietz, G.; Boon, C. Commonalities and contradictions in HRM and performance research. Hum. Resour. Manag. J. 2005, 15, 67-94. [CrossRef]

31. Shaw, J.D.; Dineen, B.R.; Fang, R.; Vellella, R.F. Employee-organization exchange relationships, HRM practices, and quit rates of good and poor performers. Acad. Manag. J. 2009, 52, 1016-1033. [CrossRef]

32. Bamberger, P.; Meshoulam, I. Human Resource Management Strategy; Sage: London, UK, 2000.

33. Walton, R.E. From Control to Commitment in the Workplace. 1985. Available online: https://hbr.org/1985/ 03/from-control-to-commitment-in-the-workplace (accessed on 11 April 2014).

34. Boon, C.; Belschak, F.D.; Den Hartog, D.N.; Pijnenburg, M. Perceived human resource management practices: Their effect on employee absenteeism and time allocation at work. J. Personal. Psychol. 2014, 13, 21-33. [CrossRef]

35. Cleveland, J.N.; Byrne, Z.S.; Cavanagh, T.M. The future of HR is RH: Respect for humanity at work. Hum. Resour. Manag. Rev. 2015, 25, 146-161. [CrossRef]

36. Ryan, R.M.; Deci, E.L. On happiness and human potentials: A review of research on hedonic and eudaimonic well-being. Annu. Rev. Psychol. 2001, 52, 141-166. [CrossRef] [PubMed]

37. King, J.E. White-collar reactions to job insecurity and the role of the psychological contract: Implications for human resource management. Hum. Resour. Manag. 2000, 39, 79-92. [CrossRef]

38. Brewster, C. Towards a 'European' Model of Human Resource Management. J. Int. Bus. Stud. 1995, $26,1-21$. [CrossRef]

39. Brewster, C. European perspectives on human resource management. Hum. Resour. Manag. Rev. 2004, 14, 365-382. [CrossRef]

40. Mayrhofer, W.; Brewster, C.; Morley, M.J.; Ledolter, J. Hearing a different drummer? Convergence of human resource management in Europe-A longitudinal analysis. Hum. Resour. Manag. Rev. 2011, 21, 50-67. [CrossRef]

41. Dirks, K.T.; Ferrin, D.L. The role of trust in organizational settings. Organ. Sci. 2001, 12, 450-467. [CrossRef]

42. Djankov, S.; La Porta, R.; Lopez-de-Silanes, F.; Shleifer, A. The law and economics of self-dealing. J. Financ. Econ. 2008, 88, 430-465. [CrossRef]

43. Visser, J. The ICTWSS Database: Database on Institutional Characteristics of Trade Unions, Wage Setting, State Intervention and Social Pacts in 34 Countries between 1960 and 2007; University of Amsterdam: Amsterdam, The Netherlands, 2011.

44. Aguinis, H.; Gottfredson, R.K.; Culpepper, S.A. Best-practice recommendation for estimating cross-level interaction effects using multilevel modeling. J. Manag. 2013, 39, 1490-1528. [CrossRef]

45. Enders, C.K.; Tofighi, D. Centering predictor variables in cross-sectional multilevel models: A new look at and old issue. Psychol. Methods 2007, 12, 121-138. [CrossRef] [PubMed]

46. Muthén, L.K.; Muthén, B.O. MPlus User's Guide, 7th ed.; Muthén and Muthén: Los Angeles, CA, USA, 2012.

47. Kogut, B.; Singh, H. The effect of national culture on the choice of entry mode. J. Int. Bus. Stud. 1988, 19, 411-432. [CrossRef]

48. Hofstede, G.; Hofstede, G.J.; Minkov, M. Cultures and Organizations, Software of the Mind, 3rd ed.; McGraw-Hill: New York, NY, USA, 2010.

49. Becker, T.E. Potential problems in the statistical control of variables in organizational research: A qualitative analysis with recommendations. Organ. Res. Methods 2005, 8, 274-289. [CrossRef]

50. Mathieu, J.E.; Aguinis, H.; Culpepper, S.A.; Chen, G. Understanding and estimating the power to detect cross-level interaction effects in multilevel modeling. J. Appl. Psychol. 2012, 97, 951-966. [CrossRef] [PubMed]

51. Peretz, H.; Levi, A.; Fried, Y. Organizational diversity programs across cultures: Effects on absenteeism, turnover, performance and innovation. Int. J. Hum. Resour. Man 2015, 26, 875-903. [CrossRef]

52. Datta, D.K.; Guthrie, J.P.; Wright, P.M. HRM and labor productivity: Does industry matter? Acad. Manag. J. 2005, 48, 135-145. [CrossRef]

53. Hauff, S.; Alewell, D.; Hansen, N.K. HRM systems between control and commitment: Occurrence, characteristics and effects on HRM outcomes and firm performance. Hum. Resour. Manag. J. 2014, 24, 424-441. [CrossRef] 
54. Hom, P.W.; Griffeth, R.W. Employee Turnover; Southwestern College Publishing Co. Inc.: Cincinnati, OH, USA, 1995.

55. Maas, C.J.; Hox, J.J. Sufficient sample sizes for multilevel modeling. Methodology 2005, 1, 86-92. [CrossRef]

56. Scherbaum, C.A.; Ferreter, J.M. Estimating statistical power and required sample sizes for organizational research using multilevel modeling. Organ. Res. Methods 2009, 12, 347-367. [CrossRef]

57. Gerhart, B. How much does national culture constrain organizational culture? Manag. Organ. Rev. 2008, 5, 241-259. [CrossRef]

(C) 2016 by the authors; licensee MDPI, Basel, Switzerland. This article is an open access article distributed under the terms and conditions of the Creative Commons Attribution (CC-BY) license (http://creativecommons.org/licenses/by/4.0/). 